\title{
Intradural Extramedullary Tuberculoma of the Spinal Cord Following Tuberculous Meningitis
}

\author{
Deok-Ki Jeong, Young-Min Kwon \\ Department of Neurosurgery, Dong-A University College of Medicine, Busan, Korea
}

Intradural extramedullary tuberculoma of the spinal cord (IETSC) is an uncommon disease which can occurs secondary to tuberculous meningitis. A 31-year-old woman was diagnosed as tuberculous meningitis after mental disorientation. Her mentality was recovered after antituberculous therapy. After 7 months of antituberculous therapy, paraplegia has developed. Magnetic resonance imaging (MRI) revealed a mass lesion between the T1 and T12 spinal levels with arachnoid thickening which results in the development of tuberculoma. She received surgical resection of IETSC followed by antituberculous therapy and neurological function has been improved. The two years after surgical treatment, spinal MRI showed syringomyelia between T1 to L1. But, her neurological outcome was not aggravated.

Key Words: Tuberculoma - Meningeal tuberculosis • Syringomyelia

\section{INTRODUCTION}

Central nervous system (CNS) involvement in tuberculosis is about $10 \%$ of patients and tuberculous meningitis is the most common manifestation ${ }^{12,16,18)}$. Intradural spinal tuberculoma consist of less than 5\% of CNS tuberculoma and intradural extramedullary tuberculoma of the spinal cord (IETSC) is extremely rare ${ }^{11)}$. So far, there are 33 cases of IETSC were reported on the literature ${ }^{4,6,9,11,12-17,19,20)}$. In this article, we report a patient with IETSC who underwent surgical resection and followed up for 2 years post-operatively.

\section{CASE REPORT}

The 31-year-old woman was presented to our institution with sudden onset of mental change. She suffered from fever and headache for 2 weeks before onset of mental change. At that time, she was pregnant $16+1$ weeks. Initially, she showed stuporous mentality which was recovered after two days. Past history of pulmonary tuberculosis (Tbc) was denied, however

- Received: March 6, 2015 - Revised: June 1, 2015

- Accepted: June 1, 2015

Corresponding Author: Young Min Kwon, MD, PhD

Department of Neurosurgery, Dong-A University College of Medicine,

26 Daesingongwon-Ro, Seo-Gu, Busan 602-812, Korea

Tel: + 82-51-240-5241, Fax: +82-51-242-6714

E-mail: ymkwon@dau.ac.kr

$\otimes$ This is an Open Access article distributed under the terms of the Creative

Commons Attribution Non-Commercial License (http://creativecommons.org/ licenses/by-nc/3.0/) which permits unrestricted non-commercial use, distribution, and reproduction in any medium, provided the original work is properly cited. active Tbc was suspicious on chest computed tomography. Lumbar cerebrospinal fluid (CSF) analysis is as followed; white blood cell count 65 (polymorphonuclear leukocyte 62\%, lymphocyte $26 \%$, monocyte $12 \%$ ), glucose $7 / 117 \mathrm{mg} / \mathrm{dL}$ (CSF/ Serum) and protein $744 \mathrm{mg} / \mathrm{dL}$. CSF Tbc polymerase chain reaction and serum $\mathrm{Tbc}$ specific antigen induced interferongamma showed positive results. She was first diagnosed as a tuberculous meningoencephalitis and anti-tuberculous (antiTbc) treatment with rifampicin, isoniazid, ethambutol, and pyrazinamide was started. Six days after the anti-Tbc treatment was started, she developed an acute sensory disturbance and paraplegia (motor grade 1/5) with bladder and bowel involvement. Spinal magnetic resonance imaging (MRI) revealed suspicious lesion of diffuse myelitis in the thoracic cord (Fig. 1). Steroid therapy with combination of anti-Tbc treatment was started and her lower extremities motor power was improved.

Twelve weeks after anti-Tbc medication started, she developed fever and decreased sensation on lower extremities. Spinal MRI showed pachymeningeal enhancement from C6 to L1 with compressed spinal cord (Fig. 2). High dose steroid medication was applied and neurological symptom was improved.

Twenty-nine weeks after anti-Tbc medication started, motor power of both lower extremities was decreased to grade $1 / 5$. Sensory was decreased below T2 level and she was not able to urinary void voluntarily. Spinal MRI showed IETSC between T1 and T12 with severe cord compression (Fig. 3). Laminotomy between T1 and T12 was performed. After opening of the dura mater, thickened arachnoid membrane was observed and yellowish tuberculoma was located underneath of arachnoid membrane. Dark and gray granuloma was observed in the dura mater (Fig. 4). There was a cleavage plane bet- 
ween tuberculoma and cord. The granulomas were gently removed. After the operation, the patient showed progressive improvement in motor power and sensation. So she was able to walk with cane assist and void and defecate without assistant. However, sensory was remained decreased. Intermittent
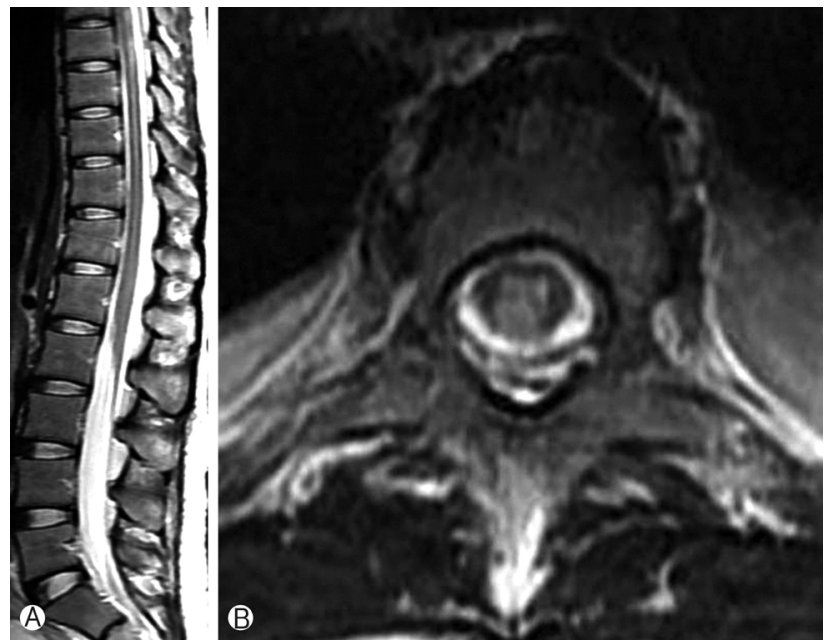

Fig. 1. T2-weighted sagittal (A) and axial (B) MR images show high signal intensity in thoracic cord.
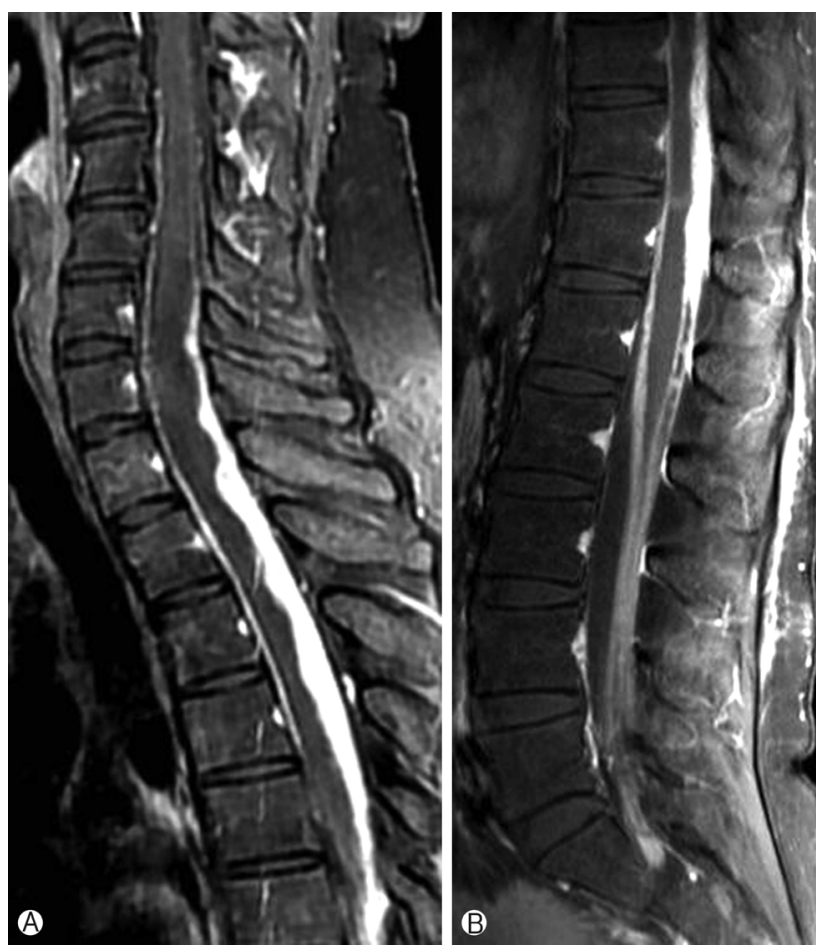

Fig. 2. Twelve weeks after anti-Tbc medication started, $\mathrm{Tl}$ contrast-enhanced sagittal MRI reveals a strong dorsal meningeal enhancement with cord compression. Dorsal meningeal enhancement starts from C6 level (A) and ends off between T12 and L1 (B). neuropathic pain on anterior chest and left arm were complained and follow-up spinal MRI was done at one and two years after surgical treatment. Spinal MRI showed syringomyelia between T1 to L1 in one year post-operation MRI (Fig $5 \mathrm{~A})$. Syringomyelia was aggravated up to upper cervical level in two year post-operation spinal MRI (Fig 5B). However, her neurological outcome was not aggravated.

\section{DISCUSSION}

Spinal involvement of tuberculous infection can be classified into four categories, ${ }^{5,11,12,18)}$ : Potts spine (spondylitis), nonosseous spinal tuberculoma (extradural, intradural extrame-

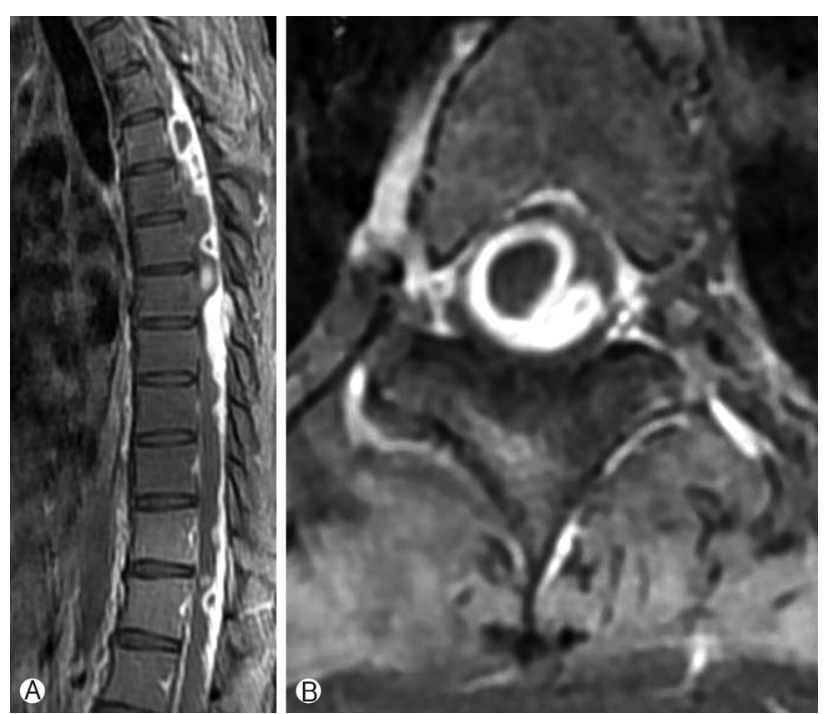

Fig. 3. Twenty-nine weeks after anti-Tbc medication started, T1 contrast-enhanced sagittal MRI (A) reveals irregular enhancement of dorsal meninx and a cystic lesion with wall enhancement. T1 contrast-enhanced axial MRI (B) shows a large size of cystic mass with wall enhancement. These lesions were extended from $\mathrm{T} 1$ to T12.

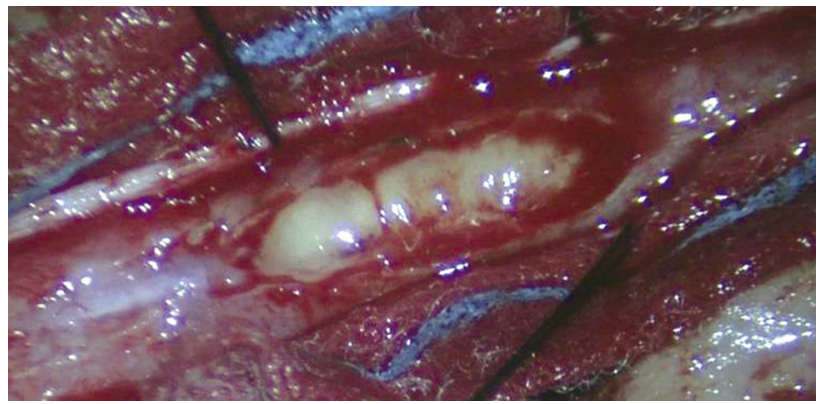

Fig. 4. The arachnoid membrane was grayish and thickened. After dissection of the arachnoid membrane, the yellow intradural extramedullary granulomas were shown. 


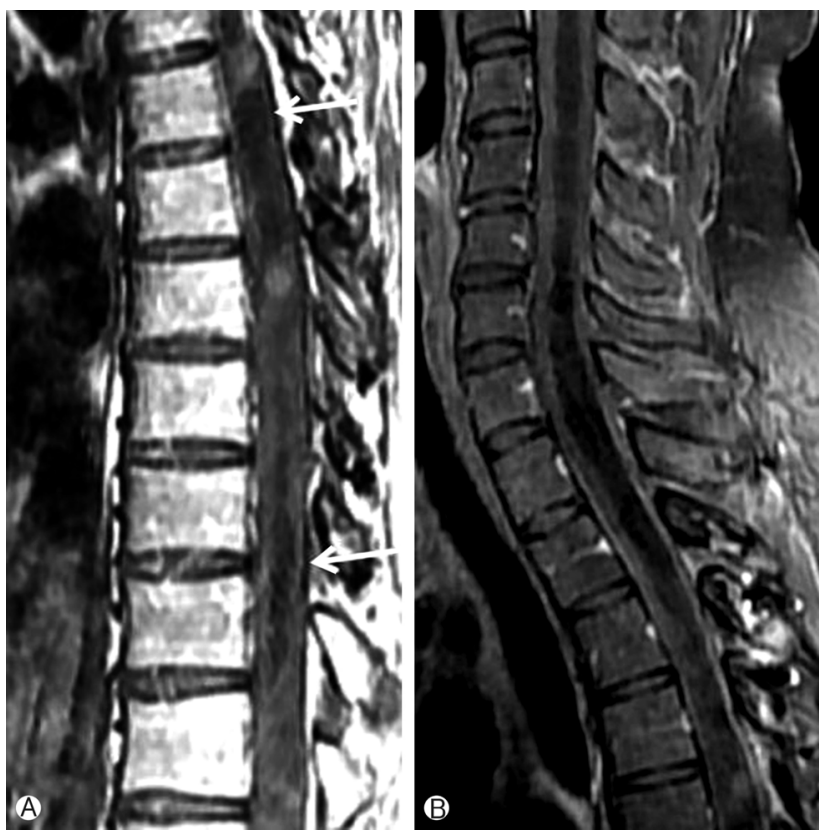

Fig. 5. T1-weighted sagittal MRI at post-operative 1 year reveals the syringomyelia (white arrow) from $\mathrm{Tl}$ to $\mathrm{L} 1(\mathrm{~A})$. $\mathrm{T1}$-weighted sagittal MRI at post-operative 2 years reveals that aggravation of syringomyelia. It was extended up to $\mathrm{Cl}(\mathrm{B})$.

dullary, intramedullary), tuberculous arachnoiditis, and tuberculous meningitis. Among these categories, occurrence of nonosseous spinal tuberculoma is extremely rare. Dastur ${ }^{3)}$ reviewed 74 cases of spinal tuberculomas and reported that 65\% (48/ 74) of tuberculomas were located at extradural, $8 \%(6 / 74)$ were intramedullary, 5\% (4/74) were intradural extramedullary and 20\%(15/74) were arachnoidal.

Roca $^{16)}$ reviewed and reported 22 cases of IETSC on 2004. Since then, 11 more cases of IETSC were reported ${ }^{4,6,9,11-17,19,20)}$. Reviewing of these 33 patients, $88 \%$ (29/33) of patients were diagnosed and treated for tuberculous meningitis. IETSC are usually developed in patients with tuberculous meningitis whereas intramedullary tuberculoma associated with pulmonary tuberculosis. IETSC occurs in young patients more commonly in both genders ${ }^{4,11,17)}$. Thoracic spine is the most common site for IETSC with a few exceptions ${ }^{11,16,17)}$. Surgical treatment of IETSC combined with medical therapy was carried out in $88 \%$ (29/33) patients. And all patients showed improvement of their neurological symptoms and deficits ${ }^{4,9,11,12,14,15,17,19)}$.

IETSC can occur at any time but most reported cases showed a paradoxical response during the course of chemotherapy, which ranged from 3 weeks to 1 year ${ }^{10,14,19)}$. The mechanism for the paradoxical response is uncertain. However, pathophysiology of the paradoxical response is due to an interaction between the host immune reaction to the mycobacterial products $^{10,14,19)}$. As the chemotherapy controls active Tbc, host- immunosuppression resolves, and then hypersensitivity to the protein derivatives of mycobacteria cause a paradoxical immune response ${ }^{10,14,19)}$. These paradoxical response leads to an ongoing inflammation in the arachnoid membrane, which results in the development of tuberculoma.

Some cases of en plaque intradural extramedullary tuberculomas were reported $^{12,14,15,18)}$. These lesions of pachymeningitis may mimic en plaque meningioma and pathology study may be mandatory for differential diagnosis of them. Our case is, so far, the only case that shows both en plaque intradural extramedullary tuberculoma and IETSC alone in a different time period. This may imply that en plaque form is the previous stage for IETSC which may be resulted after some period of times.

All the cases reported the patients' neurological results, but there are no reports in which late follow-up images were presented after treatment of IETSC. There are three reports of concurrent tuberculoma as a complication of tuberculous meningitis ${ }^{6,713)}$. Our patient showed a syringomyelia in a thoracic cord (T1-L1) at one year after surgical resection and in both cervical and thoracic cord (C1-L1) at two years after operation. However, her neurological function was gradually improved. Mechanism of syrinx formation in tuberculous meniningitis and IETSC is due to inflammatory arachoiditis. Focal scarring causes a block in the CSF circulation, resulting in forcing the CSF into the central canal of the spinal cord via Virchow Robin spaces. Also, obstruction of Virchow Robin spaces also occurs. Eventually, focal cystic dilatations in the cord eventually coalesce to form syringomyelia ${ }^{8}$. Blockage of the spinal subarachnoid CSF pathway produces a relative increase in the pressure inside the spinal cord distal to the blockage point. The pressure inside the spinal cord becomes relatively larger than that outside. Repetitive formation of this pressure gradient at each CSF pulse leads to leakage of CSF from the central canal, causing the formation of a syrinx ${ }^{1,2)}$.

\section{CONCLUSION}

IETSC is an extremely rare disease that can occur after tuberculous meningitis. IETSC develops as a result of paradoxical responses of antituberculous medication. If the patients with IETSC show neurological deficit, prompt surgical treatment results in the good prognosis.

\section{REFERENCES}

1. Chang HS, Joko M, Matsuo N, Kim SD, Nakagawa H: Subarachnoid pressure-dependent change in the syrinx size in a patient with syringomyelia associated with adhesive arachnoiditis. Case 
report. J Neurosurg Spine 2:209-214, 2005

2. Chang HS, Nakagawa H: Theoretical analysis of the pathophysiology of syringomyelia associated with adhesive arachnoiditis. J Neurol Neurosurg Psychiatry 75:754-757, 2004

3. Dastur HM: Diagnosis and neurosurgical treatment of tuberculous disease of the CNS. Neurosurg Rev 6:111-117, 1983

4. Duan J, Mao B: Unusual intradural extramedullary tuberculoma of the spinal cord in childhood. Neurol India 58:738-739, 2010

5. Gang RK: Tuberculosis of the central nervous system. Postgrad Med J 75:133-140, 1999

6. Gul S, Celebı G, Kalayci M, Acikgoz B: Syringomyelia and intradural extramedullary tuberculoma of the spinal cord as a late complication of tuberculous meningitis. Turk Neurosurg 20: 561-565, 2010

7. Hui AC, Chan YL, Kay R: Syrinx and tuberculoma formation in tuberculous arachnoiditis. Can J Neurol Sci 28:148-149, 2001

8. Kaynar MY, Kocer N, Gencosmanoglu BE, Hanci M: Syringomyelia- as a late complication of tuberculous meningitis. Acta Neurochir (Wien) 142:935-939, 2000

9. Kumar R, Kasliwal MK, Srivastava R, Sharma BS: Tuberculoma presenting as an intradural extramedullary lesion. Pediatr Neurosurg 43:541-543, 2007

10. Kumar R, Prakash M, Jha S: Paradoxical response to chemotherapy in neurotuberculosis. Pediatr Neurosurg 42:214-222, 2006

11. Luo L, Pino J: An intradural extramedullary tuberculoma of the spinal cord in a non-HIV-infected patient: case report and review of the literature. Lung 184:187-193, 2006

12. Mirzai $\mathrm{H}$ : Tuberculoma of the cervical spinal canal mimicking en plaque meningioma. J Spinal Disord Tech 18:197-199, 2005

13. Muthukumar N, Sureshkumar V: Concurrent syringomyelia and intradural extramedullary tuberculoma as late complications of tuberculous meningitis. J Clin Neurosci 14:1225-1230, 2007

14. Muthukumar N, Sureshkumar V, Ramesh VG: En plaque intradural extramedullary spinal tuberculoma and concurrent intracranial tuberculomas: paradoxical response to antituberculous therapy. Case report. J Neurosurg Spine 6:169-173, 2007

15. Ozek E, Iplkcioglu AC, Erdal M: Intradural extramedullary tuberculoma mimicking en plaque meningioma. Neurol India 57:211-212, 2009

16. Roca B: Intradural extramedullary tuberculoma of the spinal cord: a review of reported cases. J Infect 50:425-431, 2005

17. Sohn S, Jin YJ, Kim KJ, Kim HJ: Long-term sequela of intradural extramedullary tuberculoma in the thoracic dorsal spinal cord: Case Report and review of the literature. Korean J Spine 8:295-299, 2011

18. Shim DW, Oh SK, Kim TK, Chae SU: Intradural extramedullary tuberculoma mimicking en plaque meningioma. Clin Ortho Surg 2:260-263, 2010

19. Takahashi H, Ito S, Kojima S, Tanno T, Hattori T: Intradural extramedullary tuberculoma of the thoracic spine: paradoxical response to antituberculous therapy. Intern Med 47:797-798, 2008

20. Yoo YM, Lee KY, Lee SB, Cho CH, Moon MS: Intradural extramedullary tuberculoma of the spinal cord. Report of 1 case. J Korean Neurosurg Soc 11:81-88, 1982 